\title{
Effective ionization coefficients for low current dc discharges in alcohol vapours at low pressure
}

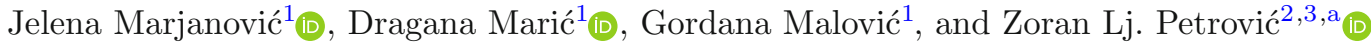 \\ 1 Institute of Physics, University of Belgrade, Pregrevica 118, 11080 Belgrade, Serbia \\ 2 School of Engineering, Ulster University, Jordanstown, Co. Antrim BT37 0QB, UK \\ 3 Serbian Academy for Sciences and Arts, Knez Mihailova 35, 11001 Belgrade, Serbia
}

Received 31 January 2021 / Accepted 26 March 2021 / Published online 29 June 2021

(C) The Author(s) 2021

\begin{abstract}
This paper presents results for effective ionisation coefficients $\left(\alpha_{\text {eff }} / N, N\right.$ - gas density) obtained from the breakdown voltage and emission profile measurements in low-pressure dc discharges in vapours of alcohols: methanol, ethanol, isopropanol, and n-butanol. Our results for $\alpha_{\text {eff }} / N$ are determined from the axial emission profiles in low-current Townsend discharge and lay in the interval of reduced electric field $E / N$ ( $E$ - electric field, $N$-gas density), from $1 \mathrm{kTd}$ to $8.8 \mathrm{kTd}$. We also give a comparison of our experimental results with those from the available literature. Our data cover the high $E / N$ range of the standard operating conditions and in the region where other data are available we have a good agreement.
\end{abstract}

\section{Introduction}

Discharges in liquids and their vapours, primarily in water and alcohols, have opened a wide field of new applications for energy sources and fuel industry $[1,2]$, for polymerization and thin-film synthesis [3], for the synthesis of nanographene layers and fast growth of carbon nanotubes [4-6], for the treatment of materials and surfaces $[7,8]$, biomedicine [7,9], applications in agriculture $[10,11]$ etc. All those applications and devices operate either in liquid, liquid-bubbles systems or with a significant gas/vapor interface, under different discharge conditions [12]. Those open new questions connected to elementary processes, dominant particles atomic and molecular collisions, surface interactions, and breakdown conditions. The elementary electron molecule collisions are often determined from fitting of the calculated swarm parameters to the experimental data. Usually, at low mean energies drift velocity and transverse diffusion normalized to electron mobility are used to determine total momentum transfer and some version of the total cross sections for inelastic processes [1316]. Use of pulsed Townsend (PT) experiments $[17,18]$ facilitated the use of drift velocities and ionization coefficients to obtain/normalize the cross section data at moderate and higher $E / N$. In particular, our group promoted fitting [19] the moderate energy range of the cross sections $5-30 \mathrm{eV}$ by adjusting the dissociative excitation while keeping the ionization cross sections as they are produced in binary collision experiments [20-24] or theory (e.g., Binary Encounter Bethe-BEB) [25]. It is important to note that the region where ion-

\footnotetext{
a e-mail: z.petrovic@ulster.ac.uk (corresponding author)
}

ization becomes relevant in ionized gas kinetics is the operating region of most plasmas, ionization is needed to compensate the losses and maintain self-sustained discharges. On the other hand, under those conditions non-conservative effects on the transport coefficients become apparent $[26,27]$ making the whole procedure more difficult. In any case ionization coefficients in this region of $E / N$ are required to set the inelastic losses of the electron ensemble and to set its mean energy.

It is known that breakdown, under dc fields and slowly varying ac fields, depends on surface collisions of ions and atoms, so the breakdown condition is a very sensitive projection of the atomic and molecular collisions [28-31]. Our research aims at providing some of the elementary data on dc breakdown and low-pressure operation regimes in a wide interval of discharge currents in alcohol vapours, for such data are scarce in the literature. In our measurements of breakdown and low-current regimes of dc discharges, we can determine coefficients for elementary processes of universal importance in all regimes of operation, such as ionization rate, secondary electron yield, excitation rates by fast neutrals, and eventually the corresponding cross sections.

In our earlier papers $[32,33]$ we have presented measurements of breakdown voltages and spatial profiles of low-current dc discharges in alcohol vapours: methanol, ethanol, isopropanol, and n-butanol as well as in water vapour. In our previous papers on alcohols, spatial emission profiles have been used to illustrate the transition between different discharge modes. In this paper we start from the axial profiles for the low current diffuse (Steady State Townsend-SST) regime recorded, as described in $[32,33]$ and produce effective ionization coefficients. 


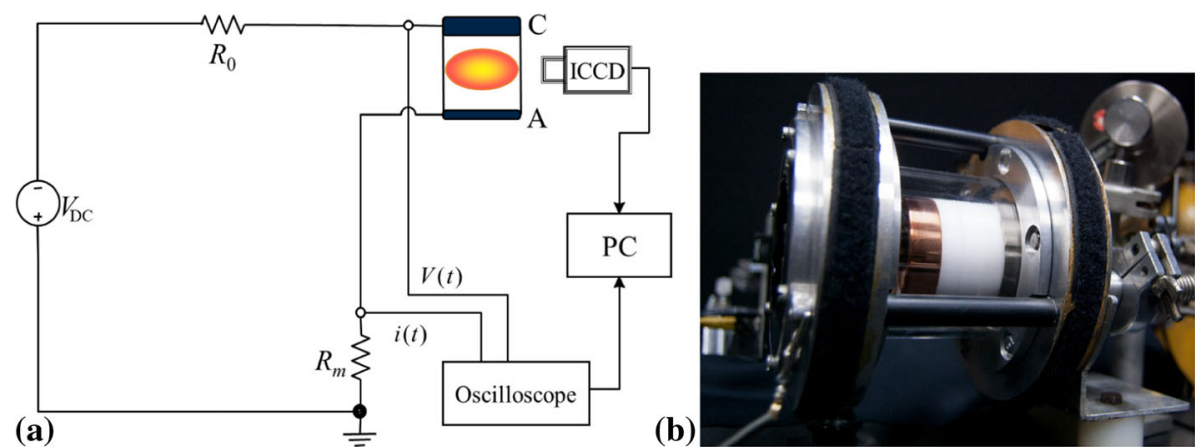

Fig. 1 a Schematics of the experimental setup and the electrical circuit used in measurements. All the recordings were made with an ICCD camera mounted with an objective lens. The series resistor $R_{0}$ is used to limit the current [37] while $R_{\mathrm{m}}$ is the "monitoring" resistor used to measure the discharge current; $\mathbf{b}$ photograph of the discharge chamber

\section{Experimental set-up}

Experimental measurements are done in a parallel-plate electrode system that is placed inside a tightly fitted quartz tube [34]. The diameter of electrodes $D$ is 5.4 $\mathrm{cm}$, the cathode $(\mathrm{C})$ is made of copper, while the anode (A) is made of quartz with a transparent, conductive platinum thin film deposited on its surface. The distance between electrodes is adjustable and the present measurements were performed with $d=1.1 \mathrm{~cm}$ and $3.1 \mathrm{~cm}$. Figure 1a shows a simplified schematic of our set-up $[33,34]$.

Construction of the discharge chamber (Fig. 1b) allows side-on measurements of emission intensity, along the longitudinal chamber axis. For recordings of light emission, we used a sensitive ICCD camera (Andor IStar DH720-18U-03) equipped with a glass lens that allows us to acquire axial discharge profiles of spectrally integrated emission in the visible range of spectrum, defined by the transparency of the lens and the quantum efficiency of the ICCD photocathode. Adding the optical filters allows us to measure profiles associated with some specific lines [32,33]. Further recordings with optical filters $(\mathrm{H} \alpha, \mathrm{CH}$ at $431.2 \mathrm{~nm})$ were done to provide us with additional information on particular processes of excitation $[32,33]$ and even the possibility to obtain absolute spatial profiles of excitation coefficients [35]. Profiles of $\mathrm{H} \alpha$ emission proved to be valuable as they show only a small contribution of fast neutrals to excitation [33], which enabled us to extend the range of measurement of effective ionization coefficients to somewhat higher $E / N$. Still, in all cases, we obtained the same ionization coefficients regardless of whether filters were used or not. We mostly used measurements of emission integrated in the visible range of the spectrum, as the statistics was the best in that case, while filters were used mainly as an internal consistency check in this paper.

Prior to the measurements, the discharge chamber is evacuated to the base pressure of $\sim 10^{-6}$ Torr, and then the cathode surface is treated by a relatively high current discharge $(30 \mu \mathrm{A})$ in low pressure (around 1 Torr) hydrogen, approximately for $30 \mathrm{~min}$, until a stable oper- ating voltage is reached. The treatment of the cathode surface is likely to remove oxide layers, although stable oxide layers such as those found on stainless steel, aluminium and copper are impossible to remove altogether but may be made more uniform Beside oxide removal, such a treatment also removes organic molecules originating from the pumping oils and other impurities from the cathode resulting in a stable surface during long periods of measurements in one day. The procedure can provide reliable and reproducible breakdown data [30,31]. Both, treatment in hydrogen discharge and measurements in alcohol vapours are done in a slow flow regime, to ensure that possible impurities formed in the discharge chamber are continuously removed.

Measurements were done for four selected alcohols: methanol, ethanol, isopropanol (2-propanol) and nbutanol. The vapours were obtained from $99.5 \%$ purity methanol, isopropanol, n-butanol, and 95\% purity ethanol. All used alcohols are pro analysi grade chemicals and for all of them water represents the most abundant declared impurity (max. 0.2\%), while other volatile impurities such as acetone, aldehydes, and formic acid (max. 0.002\%) are present in smaller quantities. The amount of gaseous impurities dissolved in the liquid were reduced by repeated pumping of the gas above the liquid sample. Although, present only in traces, there is iron $(0.0005 \%)$ and some non-volatile substances $(<0.001 \%)$ as well. However, the presence of a small amount of water vapour and of other impurities in the discharge does not affect the results [33]. The vapour is obtained from the liquid alcohol sample placed in a test tube. After opening a regulatory pressure valve, alcohol begins to boil due to the pressure difference above its surface $\left(10^{-6}\right.$ Torr $)$ and the pressure of dissolved gases in the sample itself. In this way, alcohol becomes devoid of dissolved volatile constituents. The impurities are thus reduced in the liquid sample to a minimum through the boiling and evacuating sequences. When boiling ends, vapour is maintained at a moderate pressure (lower than the vapour pressure) in the chamber for $1-2 \mathrm{~h}$ to saturate the electrodes and the chamber walls. The vapour pressures for methanol, ethanol, isopropanol, and n-butanol at room temperature are around 127, 45, 44 and 7 Torr, respectively 
[36]. The temperature in the laboratory is maintained by the air-conditioning system at the temperature of 20 degrees Celsius. In all cases we operate at pressures well below the vapour pressure (that may drastically change with variation of the temperature), so our pressure and results are not dependent on small variations of the room temperature. A more detailed description of the experimental procedure is given in $[32,33]$.

Electric circuit is designed (see our previous papers $[32,34,38])$ to provide stable operation of the discharge near the breakdown conditions [31-33,39]. The series resistor $R_{0}$ with a high resistance is used to limit current keeping it as low as possible for measurements in the Townsend discharge. The resistor $R_{\mathrm{m}}$ is used to measure the discharge current. This resistor strongly affects the oscillations of the current [28,37]. For detection of the electrical signal, we used a digital oscilloscope (Keysight Technologies DSO9104A) and two voltage probes (Tektronix P6915 and Agilent 10076A).

\section{Results and discussion}

In addition to the prebreakdown measurements [40] one can also use low-current self-sustained discharges operating in the low-current limit (no space charge, constant electric field i.e., a Steady State Townsend SST swarm experiment) to obtain the ionization coefficients. Initial stages of breakdown go through the multiplication of electrons dictated by the external field, and for the lowcurrent limit of the discharges in the dark Townsend or the low-current diffuse regime the growing space charge may be used as a perturbation to the external field distribution [28,30,41,42]. Recording of the Volt-Ampere characteristics and of the spatial profiles allow us to find the conditions where space charge effects are negligible.

Based on experimentally recorded emission profiles for the low-current limit (no space charge) of the DC discharges in the Townsend/diffuse regime (breakdown conditions) $[32,33]$, we were able to determine effective ionization coefficients. Figure 2 shows an example of an experimentally recorded emission profile in low-current Townsend discharge in methanol vapour. Exponential growth is best observed if plotted in a semi-logarithmic scale and the slope corresponds to the effective ionization coefficient $\alpha_{\text {eff }} / N$ (Fig. 2), once equilibrium with the local field is reached $[31,35,43]$. The use of emission profiles recorded at high values of reduced electron fields to determine the $\alpha_{\text {eff }} / N$ is limited due to emission in front of the cathode, coming from heavyparticle excitation, that masks the part of profile connected to electron-induced ionization and excitation $[44,45]$. Another limitation at the highest $E / N$ is due to extended equilibration distance (the flat region up to $1 \mathrm{~cm}$ in Fig. 2 that may take up a large part of the gap.

As ionization coefficient is the gas phase electron collision coefficient it should be independent of the preparation of the surfaces and the material used. This was confirmed throughout our measurements. Since the

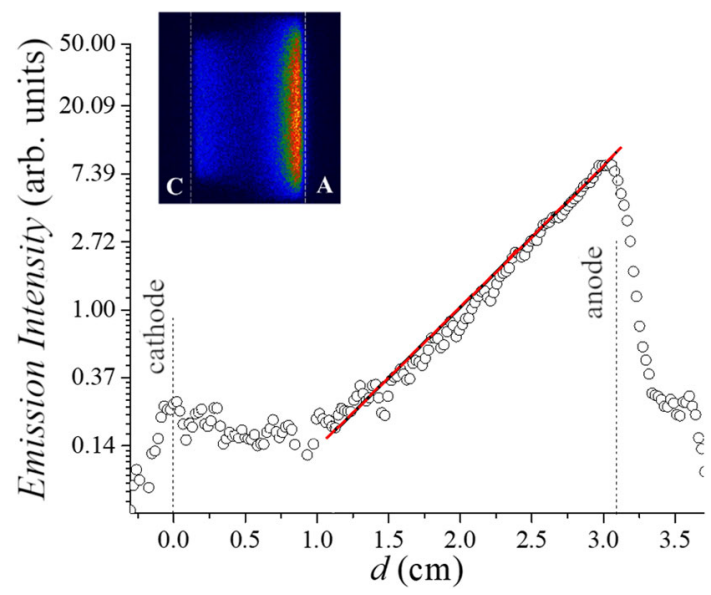

Fig. 2 2D image and axial emission profile of lowcurrent Townsend discharge recorded in methanol vapor for $p d=0.70$ Torr $\mathrm{cm}, V_{\mathrm{b}}=460 \mathrm{~V}$ and $E / N=2 \mathrm{kTd}$ at electrode distance of $d=3.1 \mathrm{~cm}$. The plot of the emission profile in the semi-log scale reflects electron multiplication between the electrodes, and the profile slope (red line) corresponds to the effective ionization coefficient

electrode material (cathode in particular) does influence the operating point and the stability of the discharge, electrode treatment was done before each set of measurements. Finally, due to absorption by the electrodes one may have an increase of the mean electron energy towards the absorbing anode that may or may not affect the ionization/excitation coefficients in the region. At the very high $E / N$ one may have reflection and secondary electron production after electron impact on the anode, resulting in a small structure adjacent to the anode. Measurements of ionization coefficients should stay clear or be able to eliminate all these possible sources of deviations from the exponential growth profiles. We made sure that none of these problems affected our measurements. Uncertainties that enter the determination of the effective ionization coefficients are only statistical and thus may be observed in the graphs. The uncertainty of $E / N$ is determined by the gap, voltage and pressure measurements and is of the order of $3 \%$.

Figure 3 shows dependence of the effective ionization coefficients $\alpha_{\text {eff }} / N$ on reduced electric field $E / N$ for the discharges in methanol, ethanol, isopropanol, and n-butanol vapours, obtained in the range of $E / N$ from 1 kTd to $8.8 \mathrm{kTd}$. For comparison we also show results for effective ionization coefficients from the literature that are available only for methanol and ethanol $[46,47]$ and [48] as compiled in [49]. Additionally, we give numerical data listed in Table 1 that correspond to the results shown in Fig. 3.

Hasegawa's and Date's results for methanol [46] cover the region of much lower values of the reduced electric fields, from $130 \mathrm{Td}$ to $3 \mathrm{kTd}$. For the overlapping range of $E / N$, our effective ionization coefficients in methanol vapor are slightly lower than those in the work of Hasegawa and Date (Fig. 3a). The difference 
(a) METHANOL

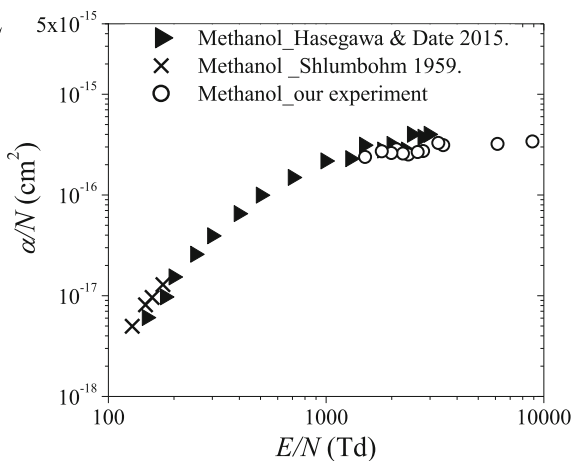

(b) ETHANOL

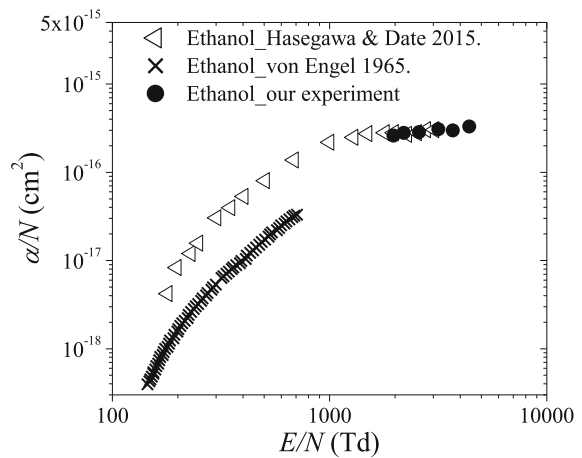

(c) all alcohols

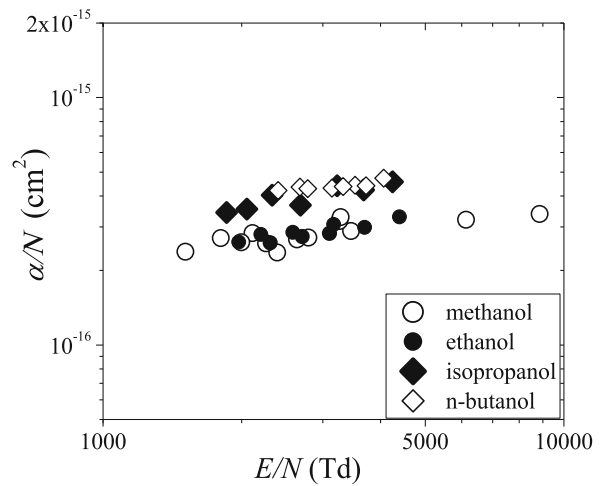

Fig. 3 The dependence of reduced effective ionization coefficient $\left(\alpha_{\text {eff }} / N\right)$ on the reduced electric field $(E / N)$. Results obtained from our experiment for a) methanol (open black circles) and b) ethanol (solid black circles) are compared with data for methanol from Hasegawa and Date [46] (solid black triangles) and Shlumbohm [47] (black X) and with data for ethanol from Hasegawa and Date [46] (open black triangles) and von Engel [49] (black X). Additionally, c) shows the results obtained from our experiment for isopropanol and n-butanol presented together with the results for methanol and ethanol

increases to almost a factor of two above $2 \mathrm{kTd}$. The results of Shlumbohm [47] for methanol (Fig. 3a) are slightly higher than those of Hasegawa and Date for the range of $E / N<200 \mathrm{Td}$, while we do not have results at such low reduced electric fields values.

In case of ethanol vapour, our results agree well with those of Hasegawa's and Date's for the $E / N$ range of 1.5-3 kTd. Furthermore, results from Hasegawa [46] and Raether [48] (as presented by von Engel in [49]), in the overlapping range of $E / N(140-700 \mathrm{Td})$, differ from each other (Fig. 3b) by a large factor, even greater than
3, the effective ionization coefficients from Raether [48] being much smaller. This disagreement may be due to differences in experiments and measurement techniques or the purity of the ethanol samples, especially having in mind that the data from Raether date from 1930s and were obtained by recording light emission from the avalanches without control of the space charge effects (that are in our case provided by the Volt- Ampere characteristics for a steady discharge).

In Fig. 3c, we present results for $\alpha_{\text {eff }} / N$ for electrons in isopropanol and n-butanol vapours. The results for effective ionization coefficients for these higher-order alcohols cover a relatively narrow and yet important range of reduced electric fields, from 1.8 to $4.3 \mathrm{kTd}$. Figure 3c also shows results for all alcohols studied in this work. In the entire $E / N$ range, effective ionization coefficients for isopropanol and n-butanol are a little higher than for the methanol and ethanol.

\section{Conclusion}

Non-equilibrium discharges and plasmas that operate in liquid media or an environment that contains vapours have become a significant subject of research due to the broad field of possible applications $[4,12,50]$. Obtaining new and improvement of existing applications require accessible data for modeling, good understanding, and an insight into elementary processes. Accordingly, in this paper, we present the results for effective ionization coefficients obtained from our experimental study of low-pressure dc breakdown in vapours of alcohols - in three primary alcohols: methanol, ethanol, n-butanol, and one secondary alcohol: isopropanol. Effective ionization coefficient is obtained from axial emission profiles in low-current Townsend discharges for conditions with dominant electron excitation of the background gas (high pressure i.e., lower $E / N$ ). Our results lay in the reduced electric field interval $1-8.8 \mathrm{kTd}$.

In the available literature, there is not much data on ionization coefficients for discharges in alcohol vapours. Based on our knowledge, the effective ionization coefficients for higher-order alcohols (isopropanol, and nbutanol), are given for the first time in this paper. For isopropanol and n-butanol, we obtained results that cover a relatively narrow range of moderate values of $E / N$ from 1.8 to $4.3 \mathrm{kTd}$.

On the other hand, for methanol and ethanol we were able to compare our results with the results from the literature. Although the $E / N$ ranges covered in our experiment and experimental measurements of Hasegawa and Date [46] in the most part do not overlap, for the interval where they do, agreement of results from both sources is reasonably good. However, we could not obtain results for $\alpha_{\text {eff }} / N$ that correspond to lower values of $E / N(E / N<1 \mathrm{kTd})$, due to limitations of the experiment and the electrical circuit components that did not allow us to have a stable dc dark Townsend discharge (i.e., without oscillations) [39]. On the other hand, our measurements have enabled extending the 
Table 1 Effective ionization coefficients obtained in our experimental measurements of discharges in vapours of alcohols: methanol, ethanol, isopropanol, and n-butanol. During the measurements, the room temperature was $T=20^{\circ} \mathrm{C}$

\begin{tabular}{|c|c|c|c|c|c|c|}
\hline & $p$ (Torr) & $V_{\mathrm{b}}(V)$ & $E / N(\mathrm{Td})$ & $\alpha$ (pairs $/ \mathrm{cm})$ & $\alpha_{\mathrm{eff}} / N \times 10^{-16}\left(\mathrm{~cm}^{2}\right)$ & $d(\mathrm{~cm})$ \\
\hline \multirow[t]{12}{*}{ Methanol } & 0.18 & 585 & 8866 & 2.03 & 3.38 & 1.1 \\
\hline & 0.22 & 505 & 6136 & 2.4 & 3.21 & 1.1 \\
\hline & 0.36 & 455 & 3453 & 3.46 & 2.89 & 1.1 \\
\hline & 0.45 & 460 & 2792 & 4.07 & 2.72 & 1.1 \\
\hline & 0.54 & 472 & 2389 & 4.25 & 2.36 & 1.1 \\
\hline & 0.63 & 488 & 2110 & 5.94 & 2.83 & 1.1 \\
\hline & 0.13 & 433 & 3278 & 1.4 & 3.28 & 3.1 \\
\hline & 0.16 & 435 & 2636 & 1.42 & 2.67 & 3.1 \\
\hline & 0.19 & 446 & 2257 & 1.64 & 2.57 & 3.1 \\
\hline & 0.22 & 460 & 1996 & 1.93 & 2.59 & 3.1 \\
\hline & 0.26 & 475 & 1802 & 2.3 & 2.7 & 3.1 \\
\hline & 0.32 & 497 & 1510 & 2.53 & 2.38 & 3.1 \\
\hline \multirow[t]{6}{*}{ Ethanol } & 0.09 & 433 & 4399 & 1.05 & 3.29 & 3.1 \\
\hline & 0.11 & 425 & 3697 & 1.11 & 2.98 & 3.1 \\
\hline & 0.13 & 417 & 3168 & 1.3 & 3.07 & 3.1 \\
\hline & 0.16 & 426 & 2583 & 1.52 & 2.85 & 3.1 \\
\hline & 0.19 & 435 & 2200 & 1.78 & 2.79 & 3.1 \\
\hline & 0.22 & 454 & 1969 & 1.94 & 2.6 & 3.1 \\
\hline \multirow[t]{7}{*}{ Isopropanol } & 0.09 & 419 & 4247 & 1.45 & 4.56 & 3.1 \\
\hline & 0.11 & 422 & 3676 & 1.57 & 4.23 & 3.1 \\
\hline & 0.13 & 426 & 3221 & 1.88 & 4.4 & 3.1 \\
\hline & 0.16 & 441 & 2682 & 1.95 & 3.67 & 3.1 \\
\hline & 0.19 & 460 & 2327 & 2.57 & 4.02 & 3.1 \\
\hline & 0.22 & 474 & 2052 & 2.64 & 3.54 & 3.1 \\
\hline & 0.25 & 489 & 1854 & 2.92 & 3.43 & 3.1 \\
\hline \multirow[t]{8}{*}{ n-butanol } & 0.09 & 402 & 4061 & 1.51 & 4.72 & 3.1 \\
\hline & 0.12 & 427 & 3719 & 1.74 & 4.39 & 3.1 \\
\hline & 0.11 & 405 & 3523 & 1.64 & 4.42 & 3.1 \\
\hline & 0.13 & 437 & 3319 & 1.87 & 4.36 & 3.1 \\
\hline & 0.12 & 414 & 3139 & 1.83 & 4.3 & 3.1 \\
\hline & 0.16 & 457 & 2781 & 2.26 & 4.26 & 3.1 \\
\hline & 0.15 & 440 & 2675 & 2.15 & 4.35 & 3.1 \\
\hline & 0.19 & 475 & 2396 & 2.69 & 4.21 & 3.1 \\
\hline
\end{tabular}

range of ionization coefficient towards higher $E / N$ values $(E / N>3 \mathrm{kTd})$. That range of $E / N$ coincides with the conditions found in discharges for numerous applications.

The obtained results for effective ionization coefficients in vapours of different alcohols, together with the breakdown, and voltage-current measurements, provide a basis to produce complete sets of cross sections and other discharge parameters that can be used in plasma modeling. In case of ethanol and methanol data for other transport coefficients exist $[46,47,51-54]$ while for the other two alcohols some additional information on cross sections or transport data may be required.

Acknowledgements The authors acknowledge support from the Serbian Ministry of Education, Science and Technological Development under project numbers OI 171037 and III 41011. Z. Lj. Petrović is grateful to the SANU project 155 and to Ulster University for support.

\section{Author contributions}

Jelena Marjanović - performed experimental measurements and calculations, analyzed the results, and wrote the draft of the manuscript. Dragana Marić-led the studies and interpretation of the results, participated in analysis, and discussion of the raw data and the results and participated in revising and writing the paper. Gordana Malović - helped in the analysis of measured data, participate in the discussion of the results, and in the editing of the manuscript. Zoran Lj. Petrović-defined the plan of research and design of experiment and development of the experimental procedure. He supervised the studies and analysis of the results, organization, and finalization of the manuscript.

Data Availability Statement This manuscript has no associated data or the data will not be deposited. [Authors' comment: This manuscript has all it's data presented in the Table 1 (in addition to figures).] 
Open Access This article is licensed under a Creative Commons Attribution 4.0 International License, which permits use, sharing, adaptation, distribution and reproduction in any medium or format, as long as you give appropriate credit to the original author(s) and the source, provide a link to the Creative Commons licence, and indicate if changes were made. The images or other third party material in this article are included in the article's Creative Commons licence, unless indicated otherwise in a credit line to the material. If material is not included in the article's Creative Commons licence and your intended use is not permitted by statutory regulation or exceeds the permitted use, you will need to obtain permission directly from the copyright holder. To view a copy of this licence, visit http://creativecomm ons.org/licenses/by/4.0/.

\section{References}

1. F. Chen, X. Huang, D. Cheng, X. Zhan, Int. J. Hydrogen Energy 39(17), 9036-9046 (2014). https://doi.org/10. 1016/j.ijhydene.2014.03.194

2. M.Z.F. Kamarudin, S.K. Kamarudin, M.S. Masdar, W.R.W. Daud, Int. J. Hydrogen Energy 38, 9438 (2013). https://doi.org/10.1016/j.ijhydene.2012.07.059

3. P. Brunet, R. Rincón, J.M. Martinez, Z. Matouk, F. Fanelli, M. Chaker, F. Massines, Plasma Process. Polym. (2017). https://doi.org/10.1002/ppap. 201700049

4. A. Ando, K. Ishikawa, H. Kondo, T. Tsutsumi, K. Takeda, T. Ohta, M. Ito, M. Hiramatsu, M. Sekine, M. Hori, Jpn. J. Appl. Phys. (2018). https://doi.org/ 10.7567/JJAP.57.026201

5. M. Matsushima, M. Noda, T. Yoshida, H. Kato, G. Kalita, T. Kizuki, H. Uchida, M. Umeno, K. Wakita, J. Appl. Phys. (2013). https://doi.org/10.1063/1.4794522

6. T. Hagino, H. Kondo, K. Ishikawa, H. Kano, M. Sekine, M. Hori, Appl. Phys. Express (2012). https://doi.org/ 10.1143/APEX.5.035101

7. I. Adamovich, S.D. Baalrud, A. Bogaerts, P.J. Bruggeman, M. Cappelli, V. Colombo, U. Czarnetzki, U. Ebert, J.G. Eden, P. Favia, D.B. Graves, S. Hamaguchi, G. Hieftje, M. Hori, I.D. Kaganovich, U. Kortshagen, M.J. Kushner, N.J. Mason, S. Mazouffre, S. Mededovic Thagard, H.-R. Metelmann, A. Mizuno, E. Moreau, A.B. Murphy, B.A. Niemira, G.S. Oehrlein, Z.Lj. Petrovic, L.C. Pitchford, Y.-K. Pu, S. Rauf, O. Sakai, S. Samukawa, S. Starikovskaia, J. Tennyson, K. Terashima, M.M. Turner, M.C.M. van de Sanden, A. Vardelle, J. Phys. D Appl. Phys. 50, 323001 (2017). https://doi.org/ 10.1088/1361-6463/aa76f5

8. F. Fumagalli, O. Kylian, L. Amato, J. Hanus, F. Rossi, J. Phys. D Appl. Phys. (2012). https://doi.org/10.1088/ 0022-3727/45/13/135203

9. K.R. Stalder, G. Nersisyan, W.G. Graham, J. Phys. D Appl. Phys. 39, 3457 (2006). https://doi.org/10.1088/ 0022-3727/39/16/S02

10. N. Puač, M. Gherardi, M. Shiratani, Plasma Process. Polym. (2018). https://doi.org/10.1002/ppap. 201700174

11. N. Puač, S. Živković, N. Selaković, M. Milutinović, J. Boljević, G. Malović, Y.LJ. Petrović, Appl. Phys. Lett. 104, 214106 (2014). https://doi.org/10.1063/1.4880360
12. P.J. Bruggeman, M. Kushner, B. Locke, H. Gardeniers, B. Graham, D. Graves, R. Hofman-Caris, D. Marić, J. Reid, E. Ceriani, D. Fernandez Rivas, J. Foster, S. Garrick, Y. Gorbanev, S. Hamaguchi, F. Iza, H. Jablonowski, E. Klimova, F. Krcma, J. Kolb, P. Lukes, Z. Machala, I. Marinov, D. Mariotti, S. Mededovic Thagard, D. Minakata, E. Neyts, J. Pawlat, Z.Lj. Petrović, R. Pflieger, S. Reuter, D. Schram, S. Schroeter, M. Shiraiwa, B. Tarabova, P. Tsai, J. Verlet, T. von Woedtke, K. Wilson, K. Yasui, G. Zvereva, Plasma Sources Sci. Technol. 25, 053002 (2016). https://doi.org/10.1088/ 0963-0252/25/5/053002

13. A.V. Phelps, Rev. Mod. Phys. 40, 399 (1968). https:// doi.org/10.1103/RevModPhys.40.399

14. R.W. Crompton, Advances in atomic, molecular, and optical. Physics 33, 97 (1994). https://doi.org/10.1016/ S1049-250X(08)60034-8

15. R.W. Crompton, Aust. J. Phys. 25(4), 409 (1972). https://doi.org/10.1071/PH720409

16. L.G.H. Huxley, R.W. Crompton, The Diffusion and Drift of Electrons in Gases (Wiley, New York, 1974)

17. R.D. White, M.J. Brunger, N.A. Garland, R.E. Robson, K.F. Ness, G. Garcia, J. de Urquijo, S. Dujko, Z.Lj. Petrović, Eur. Phys. J. D 68, 125 (2014). https://doi. org/10.1140/epjd/e2014-50085-7

18. M.J.E. Casey, P.W. Stokes, D.G. Cocks, D. Bosnjaković, I. Simonović, M.J. Brunger, S. Dujko, Z.Lj. Petrović, R.E. Robson and R.D. White, Plasma Sources Sci. Technol. 30, 035017 (2021). https://doi.org/10.1088/ 1361--6595/abe729

19. O. Šašić, S. Dupljanin, J. de Urquijo, Z.Lj. Petrović, J. Phys. D Appl. Phys. 46, 325201 (2013). https://doi. org/10.1088/0022-3727/46/32/325201

20. L.J. Kieffer, JILA Information Center Report University of Colorado, Boulder, CO. USA 13 (1973)

21. L.G. Christophorou, S.R. Hunter, in Electron Molecule Interactions and their Applications, vol. 2, edited by L.G. Christophorou (Academic, New York, 1984), p. 317

22. S.R. Hunter, L.G. Christophorou, in Electron Molecule Interactions and their Applications, vol 2, edited by L.G. Christophorou (Academic, New York, 1984), p. 89

23. Y. Sakai, Appl. Surf. Sci. 192, 327 (2002). https://doi. org/10.1016/S0169-4332(02)00034-X

24. R.D. White, R.E. Robson, M.A. Morrison, B. Li, K.F. Ness, J. Phys Conf. Ser. (2007). https://doi.org/10. 1088/1742-6596/71/1/012004

25. R.L. Merlino, S.-H. Kim, J. Chem. Phys. (2008). https://doi.org/10.1063/1.3039078

26. Z.Lj. Petrović, S. Dujko, D. Marić, G. Malović, ŽNikitović, O. Šašić, J. Jovanović, V. Stojanović, M. Radmilović-Rađenović, J. Phys. D Appl. Phys. 42, 194002 (2009). https://doi.org/10.1088/0022-3727/42/ $19 / 194002$

27. R.E. Robson, Aust. J. Phys. 44, 685 (1991). https:// doi.org/10.1071/PH910685

28. A.V. Phelps, Z.Lj. Petrović, B.M. Jelenković, Phys. Rev. E 47, 2825 (1993). https://doi.org/10.1103/PhysRevE. 47.2825

29. J.S. Townsend, The Theory of Ionization of Gases by Collision (Constable, London, 1910)

30. A.V. Phelps, Z.Lj. Petrović, Plasma Sources Sci. Technol. 8, 21 (1999). https://doi.org/10.1088/0963-0252/ $8 / 3 / 201$ 
31. D. Marić, M. Savić, J. Sivoš, N. Škoro, M. Radmilović-Řadjenović, G. Malović, Z.Lj. Petrović, Eur. Phys. J. D 68, 155 (2014). https://doi.org/10.1140/ epjd/e2014-50090-x

32. J. Sivoš, D. Marić, N. Škoro, G. Malović, Z.Lj. Petrović, Plasma Sources Sci. Technol. 28, 055011 (2019). https://doi.org/10.1088/1361-6595/ab0952

33. J. Sivoš, D. Marić, G. Malović, Z.Lj. Petrović, Eur. Phys. J. D 74, 64 (2020). https://doi.org/10.1140/epjd/ e2020-100540-3

34. D. Marić, G. Malović, Z.Lj. Petrović, Plasma Sources Sci. Technol. 18, 034009 (2009). https://doi.org/10. 1088/0963-0252/18/3/034009

35. G. Malović, A. Strinić, S. Živanov, D. Marić, Z.Lj. Petrović, Plasma Sources Sci. Technol. 12, 1 (2003). https://doi.org/10.1088/0963-0252/12/4/399

36. R.C. Weast, Handbook of Chemistry and Physics, 51st edn. (Chemical Rubber Co, Cleveland, 1970)

37. Z.Lj. Petrović, A.V. Phelps, Phys. Rev. E 47, 2806 (1993). https://doi.org/10.1103/PhysRevE.47.2806

38. N. Škoro, D. Marić, G. Malović, W.G. Graham, Z.Lj. P̌etrović, Phys. Rev. E 84, 055401 (2011). https://doi. org/10.1103/PhysRevE.84.055401

39. Z.Lj. Petrović, A.V. Phelps, Phys. Rev. E 56, 5920 (1997). https://doi.org/10.1103/PhysRevE.56.5920

40. R.W. Crompton, J. Dutton, S.C. Haydon, Nature 176, 1079 (1955). https://doi.org/10.1038/1761079a0

41. M.M. Nikolić, A.R. Đorđević, I. Stefanović, S. Vrhovac, Z.Lj. Petrovic, IEEE Trans. Plasma Sci. 31, 717 (2003) https://doi.org/10.1109/TPS.2003.815467

42. J. Sivoš, N. Škoro, D. Marić, G. Malović, Z.Lj. Petrović, J. Phys. D Appl. Phys. 48, 424011 (2015). https://doi. org/10.1088/0022-3727/48/42/424011
43. T. Kuschel, I. Stefanović, G. Malović, D. Marić, Z.Lj. Petrović, Plasma Sources Sci. Technol. 22, 045001 (2013). https://doi.org/10.1088/0963-0252/22/ $4 / 045001$

44. B.M. Jelenković, A.V. Phelps, J. Appl. Phys. 85, 7089 (1999). https://doi.org/10.1063/1.370516

45. B.M. Jelenković, A.V. Phelps, Phys. Rev. A 36, 5310 (1987). https://doi.org/10.1103/PhysRevA.36.5310

46. H. Hasegawa, H. Date, J. Appl. Phys. (2015). https:// doi.org/10.1063/1.4916606

47. H. Schlumbohm, Z. Angew. Physik 11, 156 (1959)

48. H. Raether, Zeitschrift Für Physik 107, 91 (1937). https://doi.org/10.1007/BF01330230

49. A. von Engel, Ionized Gases (Clarendon Press, Oxford, 1965), p. 325

50. D.M. Fadzillah, S.K. Kamarudin, M.A. Zainoodin, M.S. Masdar, Int. J. Hydrogen Energy 44, 3031 (2019). https://doi.org/10.1016/j.ijhydene.2018.11.089

51. M.G. Curtis, 1.C. Walker, J. Chem. Soc. Faraday Trans. 88(19), 2805 (1992). https://doi.org/10.1039/ FT9928802805

52. A. Peisert, F. Sauli, European Organization for Nuclear Research (CERN) Report No. CERN-84-08 15, 24 (1984)

53. M.J. Brunger, Int. Rev. Phys. Chem. 36(2), 333 (2017). https://doi.org/10.1080/0144235X.2017.1301030

54. R. Rejoub, C.D. Morton, B.G. Lindsay, R.F. Stebbings, J. Chem. Phys. 118, 1756 (2003). https://doi.org/10. 1063/1.1531631 